\title{
A Novel Folate-Targeted Nanoliposomal System of Doxorubicin for Cancer Targeting
}

\author{
Atul A. Lohade, ${ }^{1}$ Rajesh R. Jain, ${ }^{1}$ Krishna Iyer, ${ }^{2}$ Sushant K. Roy, ${ }^{3}$ Hemant H. Shimpi ${ }^{3}$ Yogita Pawar, ${ }^{3}$ \\ M. G. R. Rajan, ${ }^{3}$ and Mala D. Menon ${ }^{1,4}$
}

Received 5 July 2015; accepted 1 December 2015; published online 21 December 2015

\begin{abstract}
Targeted drug delivery systems for cancer improves anti-tumor efficacy and reduces systemic toxicity by restricting availability of cytotoxic drugs within tumors. Targeting moieties, such as natural ligands (folic acid, transferrin, and biotin) which are overexpressed on tumors, have been used to enhance liposome-encapsulated drug accumulation within tumors and resulted in better control. In this report, we explored the scope of targeting ligand folic acid, which is incorporated in liposome systems using folic acidmodified cholesterol (CPF), enabled highly selective tumor-targeted delivery of liposome-encapsulated doxorubicin and resulted in increased cytotoxicity within tumors. Folate-tagged poloxamer-coated liposomes (FDL) were found to have significantly higher cellular uptake than conventional poloxamer-coated liposomes (DL), as confirmed by fluorometric analysis in B16F10 melanoma cells. Biodistribution study of the radiolabeled liposomal system indicated the significantly higher tumor uptake of FDL as compared to DL. Anti-tumor activity of FDL against murine B16F10 melanoma tumor-bearing mice revealed that FDL inhibited tumor growth more efficiently than the DL. Taken together, the results demonstrated the significant potential of the folate-conjugated nanoliposomal system for drug delivery to tumors.
\end{abstract}

KEY WORDS: bioconjugation; cancer targeting; doxorubicin; folic acid; liposomes.

\section{INTRODUCTION}

Chemotherapy is the most important and established mode of treatment for cancer. However, the major problem with chemotherapeutic agents is their lack of specificity and selectivity (1-3). In recent times, a lot of efforts have been directed to improve the specificity of anticancer agents, based on the morphological and physiological differences between malignant and normal tissues (4). Malignant tissue has a leaky vasculature, which allows the cells to permit rapid movement of micro and macromolecules across them; this phenomenon is called enhanced permeability and retention (EPR) effect. Passive targeting is achieved using EPR effect whereby macromolecules and micro/nano particulates (typically liposomes and nanoparticles) tend to accumulate in tumor tissue much more than they do in normal tissues.

The rapid growing tumor cells require various nutrients and vitamins in large quantities for rapid development, and hence, they overexpress many tumor-specific receptors

\footnotetext{
$\overline{{ }^{1} \text { Department of Pharmaceutics, Bombay College of Pharmacy, }}$ Kalina, Santacruz (E), Mumbai, 400098, Maharashtra, India.

${ }^{2}$ Department of Pharmaceutical Chemistry, Bombay College of Pharmacy, Kalina, Santacruz (E), Mumbai, 400098, India.

${ }^{3}$ Radiation Medicine Centre, Tata Memorial Centre, Parel, Mumbai, 400012, India.

${ }^{4}$ To whom correspondence should be addressed. (e-mail: maladmbcp@yahoo.co.in,maladmbcp@gmail.com)
}

(eg., folate, biotin, transferrin, EGF) (3). These targets can be used to deliver cytotoxic agents into tumors. Vitamins like folic acid are required for the growth of cells as they are used in various metabolic cycles to synthesize different amino acids. An active targeting can thus be achieved by attaching the ligand for overexpressed receptors on the surface of delivery systems for enhanced uptake by tumor cells.

In the present research, active targeting approach using folic acid as the ligand has been explored. Several studies have shown that more than $80-90 \%$ of ovarian tumors overexpress folic acid receptors (FR) $(5,6)$. In addition, other gynecological cancers as well as pediatric ependymal brain tumors, mesothelioma, and breast, colon, renal, lung tumors, and acute myelogenous leukemia also overexpress FR (7-9). The total number of tumors that express FR is very large; therefore, FRtargeted strategies could have significant beneficial impact on treatment of several types of cancer (10). FR is a useful target for tumor-specific drug delivery, because it is upregulated in many human cancer, and access to the folate receptor in normal tissues that express it can be low due to its location on the apical (externally facing) membrane of polarized epithelia. Moreover, folate receptor density appears to augment as the stage/grade of the cancer worsens. Hence, complicated therapy of cancer may be treated by a more straightforward approach of targeting using folate-linked therapeutics (10).

The lipid bilayer structure of liposomes is easily amenable to surface modifications by conjugating with various ligands like antibodies, antibody fragments, vitamins, glycoproteins, 
peptides (RGD sequences), and oligonucleotide aptamers, and active targeting to cancer cells is possible with such ligand-tagged liposomes (11).

Also, liposomal delivery systems are reported to be taken up by the reticuloendothelial system (RES). Surface modification of liposomes by coating them with hydrophilic polymers like PEGs and polaxamers (stealth liposomes) is one of the methods to avoid RES uptake (12).

Several attempts to develop folic acid-based liposomal delivery systems are reported, which have revealed enhanced uptake of folate-tagged delivery systems as compared to untagged delivery systems in in vitro cell uptake studies (10). Initially, PEG tagged with folic acid (folic-PEG) was linked to phosphatidylamine (PE) to yield ligand-tagged lipid (folatePEG-PE), which was then incorporated into the liposomal bilayer. Apart from PE, folic acid-linked distearoyl phosphatidylethanolamine (DSPE) has also been explored (13). Cholesterol is used in the preparation of liposomes to provide rigidity to the bilayer membrane. Attempts are also reported to link folic acid to cholesterol such as folate-PEG-cholesterol and folate-PEG-cholesteryl hemisuccinate $(13,14)$. Studies with PEG as linker to attach folic acid with polylactic acid are also reported (15).

Biodistribution studies of radiolabeled folatederivatized liposomes (folate-PEG-chol) has been compared with that of nontargeted liposomes in a murine tumor model, where in both targeted and non targeted liposomes have shown the same level of enhanced uptake in tumor $(13,16)$. All studies report, conjugation of folic acid to lipid or polymer using PEG as a linker. The present study aimed at the exploration of a small linker p-aminobenzylamine for conjugation of folic acid with cholesterol and then the subsequent incorporation in liposomes. This conjugation approach with p-aminobenzylamine provides simplicity and versatility and can be applied to different targeting ligands.

The objective of present investigation was to develop and evaluate the potential of folate-tagged liposomal delivery systems for active targeting to cancer cells using doxorubicin (DOX) as model anticancer agent.

\section{MATERIALS AND METHODS}

Cholesterol chloroformate, folic acid, and cholesterol were purchased from Sigma Aldrich (Mumbai, India); DOX was a gift from Naprod Life Sciences Ltd. (Mumbai, India); dimethyl sulfoxide (DMSO), dicyclohexyl carbodiimide (DCC) n-hydroxy succinamide (NHS), diethyl ether, hexane, ethyl acetate, butanol, glacial acetic acid, and sodium dodecyl sulfate solution (SDS) were purchased from S.D. Fine Chem Ltd. (Mumbai, India). Trehalose (Hayashibara, Japan) was supplied as gift sample by Gangwal Chemicals Pvt. Ltd (Mumbai, India). Folate-free DMEM medium, trypsin EDTA, and fetal bovine serum (FBS) were obtained from Himedia Ltd. (Mumbai, India). All other chemicals and reagents used were of analytical grade. All the animal studies were approved by independent ethics committee of Bhabha Atomic Research Centre, Mumbai, India. All the procedures involved in the animal studies were performed in accordance with the recommendations of NIH guidelines for the proper use and care of laboratory animals.

\section{Cell Lines and Animals}

A549 human lung cancer cell line and B16F10, a murine melanoma cell line, were obtained from National Centre for Cell Sciences (Pune, India) and were cultured in DMEM supplemented with $10 \%$ (v/v) heat-inactivated fetal bovine serum. The cultures were sustained at $37^{\circ}$ in a humidified incubator containing 5\% $\mathrm{CO}_{2}$. Female C57BL6 mice (6-8week old) were obtained from Advanced Centre for Treatment, Research, and Education in Cancer (Mumbai, India).

\section{Synthesis of Folic Acid-Modified Cholesterol}

The folic acid conjugation to cholesterol was carried out in two steps. In the first step, cholesterol was conjugated to p-aminobenzylamine (PABA), and the cholesterol-PABA conjugate was further reacted with folic acid to obtain the product, CPF. The conjugation of cholesterol to p-aminobenzylamine was carried with some modifications (17). Briefly, cholesterol choroformate $(1.13 \mathrm{mmol})$ and triethylamine $(4.44 \mathrm{mmol})$ were dissolved in chloroform. To this, PABA (122.4 mmol) dissolved in chloroform was added slowly. Addition was carried out at $5-15^{\circ} \mathrm{C}$. Reaction mixture was stirred using overhead stirrer (Remi India Ltd., Mumbai, India) for $30 \mathrm{~min}$, at the same temperature; this was followed by 15 -min stirring, at room temperature. The reaction was monitored by TLC. Mobile phase used for TLC was hexane:ethyl acetate (95:5). Further, the reaction mixture was washed thrice with water to remove unreacted material, then dried over sodium sulfate (anhydrous), and cholesterolconjugated p-aminobenzylamine (CP) was isolated by column chromatography using silica gel (200-400 mesh). The mobile phase used for separation by column chromatography was hexane:ethyl acetate $(8: 2)$.

Further, the folic acid conjugation of $\mathrm{CP}$ was carried out using by a previously reported method with slight modifications (18). Briefly, folic acid (FA) $(0.227 \mathrm{mmol})$ was dissolved in dimethyl sulfoxide (DMSO). To this, dicyclohexyl carbodiimide (DCC) $(0.227 \mathrm{mmol})$ and $\mathrm{n}$-hydroxy succinamide (NHS) $(0.227 \mathrm{mmol})$ were added, and the reaction mixture was stirred for $12 \mathrm{~h}$ using a magnetic stirrer, in dark under nitrogen atmosphere, at room temperature.

After $12 \mathrm{~h}, \mathrm{CP}$ (0.227 mmol dissolved in chloroform and then diluted with DMSO), was added to the above reaction mixture and stirred for another $24 \mathrm{~h}$ under the same conditions. Reaction was monitored by TLC. Mobile phase used for TLC was butanol:water:glacial acetic acid (6:1.5:3 ml). Chloroform from the reaction mixture was evaporated on rotary evaporator (Superfit, Mumbai, India). DMSO from the reaction mixture was removed by extracting the product with chilled diethyl ether, followed by evaporation of diethyl ether on rotary evaporator (Superfit, Mumbai, India) to obtain product. The synthesized compounds were confirmed by ${ }^{1} \mathrm{H}$ NMR analysis.

\section{Preparation of Folic Acid-Tagged Liposomal System}

Folate-tagged liposomes (FDL) were prepared by remote loading method using ammonium sulfate as described previously by Haran et al. (19) with slight modifications. In brief, required quantities of Phospholipon 90G and Phospholipon 
$90 \mathrm{H}$ and cholesterol/folate-modified cholesterol (CPF) (0.9/ $0.6 / 0.5)$ were dissolved in chloroform: methanol mixture (1:1). The lipid solution was evaporated on a rotary evaporator (Buchi India Ltd, Mumbai, India) to remove organic solvents, and thin film was dried under vacuum for $2 \mathrm{~h}$. This formed film was hydrated using ammonium sulfate above the phase transition temperature of the phospholipids $(60 \pm$ $2^{0}$ ) to form the liposomes. Excess ammonium sulfate was removed by centrifugation $\left(21,700 \mathrm{~g}\right.$ at $4^{\circ} \pm 2^{\circ} \mathrm{C}$ for $\left.30 \mathrm{~min}\right)$ (Beckman Coulter, U.S.A.), and desired particle size of liposomes was achieved by probe sonication (Branson India Ltd., Mumbai, India). Liposomes formed were incubated at $60 \pm$ $2^{\circ} \mathrm{C}$ with DOX solution. Unentrapped DOX was removed by centrifugation $\left(34,000 \mathrm{~g}\right.$ at $40 \pm 20^{\circ} \mathrm{C}$ for $45 \mathrm{~min}$ ) (Beckman Coulter, U.S.A.). The liposomal dispersion was then mixed with $1 \%$ poloxamer F127, and the mixture was kept overnight at room temperature. Freeze drying (VirTis bench top model, USA) of the liposomal system was carried out using trehalose as a cryoprotectant. The plain doxorubicin-loaded liposomes (DL), and folate-tagged doxorubicin-loaded liposomes (FDL) were optimized to achieve maximum entrapment and optimum particle size distribution.

\section{Characterization of Delivery Systems}

\section{Appearance and DOX Content}

The developed systems were characterized with respect to physical appearance, ease of redispersion, and sedimentation behavior. Drug content and DOX leakage after rehydration were estimated by centrifugation at $34,000 \mathrm{~g}$ at $4 \pm 2^{\circ} \mathrm{C}$ for 30 min followed by analysis DOX content in the supernatant and pellet by HPLC at $254 \mathrm{~nm}$ (Dionex HPLC, India).

\section{Size and Morphology of Liposomes}

Particle size was determined by photon correlation spectroscopy on N5 plus submicron particle size analyzer (Beckman Coulter, USA) at $25^{\circ} \mathrm{C}$. All measurements were taken by scattering light at $90^{\circ} \mathrm{C}$ in triplicate.

The liposome morphology was observed using a transmission electron microscope (TEM). Samples for TEM were prepared on formvar-coated 300-mesh size copper grid (SPI suppliers, West Chester, PA, USA). Thin aqueous film blotted with filter paper was prepared with a drop of liposomal suspension. The excess of liposomes was drawn off by tissue paper held at $90^{\circ}$ to the plane of grid. The stained grid was air dried and observed. Image was visualized on screen under the electron microscope (Philips CM200, USA) and photographed.

\section{DOX Release from Liposome}

The release profile of DOX from liposomes was assessed by the dialysis bag method using USP type I dissolution apparatus in phosphate buffered saline $\mathrm{pH} 7.4(50 \mathrm{ml})$ medium. Reconstituted freeze dried liposomal suspension corresponding to $500 \mu \mathrm{g}$ of DOX, filled in a dialysis bag (Himedia, India; molecular weight cut off 12,000-14,000 Da) and both ends were tied, was placed in the basket of the dissolution apparatus. RPM and temperature of water bath were set at $50 \mathrm{rpm}$ and $37 \pm 0.5^{\circ} \mathrm{C}$, respectively. The aliquots $(0.5 \mathrm{ml})$ were withdrawn at periodic intervals up to $48 \mathrm{~h}$ and analyzed for DOX content by HPLC at $254 \mathrm{~nm}$.

\section{Residual Solvents}

The levels of residual organic solvents (methanol and chloroform) within the liposome samples were determined by GC analysis (Varian CP-3800-GC, USA). The analyses were performed using the static head-space method using Varian WS $\mu$ software.

\section{Differential Scanning Calorimetry}

Differential scanning calorimetry (DSC) experiments were performed using a differential scanning calorimeter (Mettler Toledo DSC 822, USA). An accurately measured amount of each of the selected freeze dried liposomal samples (5-10 mg) was loaded in an aluminum pan with a central pin hole under dynamic nitrogen (purity: 99.999\%, supplier; Mars Gas Ltd, Mumbai, India) purged at $40 \mathrm{~mL} / \mathrm{min}$. An empty aluminum pan was used as reference. Pans were sealed using crimper. The sample was heated from $30^{\circ}$ to $250^{\circ} \mathrm{C}$ at a rate of $10^{\circ} \mathrm{C} / \mathrm{min}$. Measurements were performed in triplicate.

\section{In Vitro Cell Line Studies}

\section{Receptor Expression}

The expression of the folate receptor on $\mathrm{B} 16 \mathrm{~F} 10$ cells was evaluated by fluorometry cell uptake assay (20,21). Briefly, monolayer cell culture of B16F10 cells was grown in folatefree DMEM medium. Cells were harvested from subconfluent culture using trypsin EDTA (1\%) solution and then suspended in DMEM media containing 10\% FBS. An aliquot of $200 \mu \mathrm{l}$ containing $1 \times 10^{5}$ cells was transferred to two micro centrifuge tubes. In one tube FDL (equivalent to $50 \mu \mathrm{g} / \mathrm{ml}$ of DOX) was mixed with the cells while, in another tube, along with FDL (equivalent to $50 \mu \mathrm{g} / \mathrm{ml}$ of DOX), $100 \mu \mathrm{l}$ of $1-\mathrm{mM}$ folic acid solution was added. Micro centrifuge tubes were then incubated at $37^{\circ} \mathrm{C}$ and $5 \% \mathrm{CO}_{2}$ for $2 \mathrm{~h}$ with intermittent shaking after every half hour. After treatment, the cells were washed three times with phosphate buffered saline (PBS) and lysed with $1 \%$ Triton X-100 solution, and the fluorescence intensity of DOX associated with the cells in each tube was measured on Synergy ${ }^{\mathrm{HT}}$ multidetection microplate reader (BioTek Instruments Inc. Winooski, USA). The excitation and emission wavelengths were set at 530 and $590 \mathrm{~nm}$, respectively. Cellular uptake of the liposomal DOX formulations was quantified by the fluorescence intensity.

\section{Cell Uptake Process}

To evaluate the targeting potential of developed delivery systems in vitro, cell uptake studies of DOX, poloxamercoated untagged DL, and FDL were carried out in B16F10 melanoma cells at a final DOX concentration of $100 \mu \mathrm{g} / \mathrm{ml}$. For uptake of the delivery systems and DOX, the process followed was same as described for receptor expression (Appearance and DOX Content section). 
Cell uptake study was also qualitatively performed. Briefly, monolayer cell culture of B16F10 cells was grown in folatefree DMEM medium. Cells were harvested from subconfluent culture using trypsin EDTA (1\%) solution and suspended in folate-free DMEM medium containing 10\% FBS. Cell suspension was diluted appropriately according to cell count. An aliquot of $500 \mu \mathrm{l}$ containing $2 \times 10^{5}$ cells was transferred on autoclaved cover slip placed in each well of six-well tissue culture plate. After this, $3.5 \mathrm{ml}$ of DMEM medium was added, to each well of the culture plate, and incubated overnight at $37^{\circ} \mathrm{C}$ and $5 \% \mathrm{CO} 2$. After incubation, the medium was replaced from each well with $200-\mu 1$ medium containing various delivery systems along with FDL, DL, and DOX, and was mixed with the cells at a final DOX concentration of $50 \mu \mathrm{g}$. The culture plate was then incubated at $37^{\circ} \mathrm{C}$ and $5 \% \mathrm{CO} 2$ for $2 \mathrm{~h}$. After incubation, medium was removed, and cells were washed three times with PBS. Cover slips containing treated cells were taken out from the culture plate and observed under the inverted microscope with fluorescence attachment (Zeiss, Germany).

\section{Optimization of Ligand Content in Delivery System}

To evaluate the optimum concentration of folate in the targeted delivery system in vitro, cell uptake studies of the tagged delivery system were carried out with varying concentrations of ligand in the delivery system. Liposomes with varying concentrations of folate were prepared $(0.5,1$, and $2 \%)$ and subjected to cell uptake studies as describe in Appearance and DOX Content section.

\section{Cytotoxicity Assay}

The cytotoxicity assay was carried out in A549 human lung cancer cell lines and B16F10 murine lung carcinoma cell lines (22).

A549 cells and B16F10 cells $(1.0 \times 104$ cells/well $)$ were seeded in a 96-well plate and grown in DMEM containing $10 \%$ FBS (v/v) overnight at $37^{\circ} \mathrm{C}$ and $5 \% \mathrm{CO}_{2}$. Free DOX and DOX-liposome (DL and FDL) were added, and the cells were incubated at $37^{\circ} \mathrm{C}$ and $5 \% \mathrm{CO}_{2}$ for $48 \mathrm{~h}$. After incubation, cell viability was evaluated by assay with MTT [2-(2methoxy-4-nitrophenyl)-3-(4-nitrophenyl)-5-(2,4disulfophenyl)-2H-tetrazolium, monosodium salts]. Medium from each well was removed, and MTT $(0.5 \mathrm{mg} / \mathrm{ml})$ was added to each well. Plate was incubated for another $4 \mathrm{~h}$ at $37^{\circ} \mathrm{C}$ and $5 \% \mathrm{CO}_{2}$. MTT solution from each well was then replaced by $10 \%$ sodium dodecyl sulfate solution (SDS) to dissolve the formazan crystals converted from MTT by live cells. The plate was then read on Synergy ${ }^{\mathrm{HT}}$ multidetection microplate reader (BioTek Instruments Inc. Winooski, USA), and cell viability was determined from absorbance at $570 \mathrm{~nm}$. Plots of percent cell growth inhibition $v s$. concentration of DOX were plotted, and $\mathrm{IC}_{50}$ values were calculated.

\section{In Vivo Studies}

\section{Acute Toxicity Studies}

The study was approved by independent Animal Ethics Committee of Bombay College of Pharmacy, and experiment was performed as per the OECD guidelines. Swiss Albino mice (25-35 g) were administered with DOX and FDL by IV route (dose, $6 \mathrm{mg} / \mathrm{kg}$ ) through tail vein. Animals were observed and monitored over a period of 2 weeks for mortality, body weight, and any abnormal behavior such as tremors, convulsions, salivation, and diarrhea. They were sacrificed on the $14^{\text {th }}$ day; weight of all vital organs was taken, and histopathological evaluation of heart tissue was carried out.

\section{Biodistribution Studies}

Radiolabeling of the Delivery System. Untagged and tagged liposomes were labeled with ${ }^{99 \mathrm{~m}} \mathrm{Tc}$ after reduction with stannous chloride $\left(\mathrm{SnCl}_{2}\right)$. Briefly, freeze dried liposomes (DL and FDL) were dispersed in saline, and $0.1 \mathrm{ml}$ of $\mathrm{SnCl}_{2}$ in $0.01 \mathrm{M} \mathrm{HCl}$ was added to it. Mixture was shaken well, followed by addition of $0.1 \mathrm{ml}$ of ${ }^{99 \mathrm{~m}} \mathrm{Tc}(\sim 3 \mathrm{mCi})$ in saline. The reaction mixture was incubated for $10 \mathrm{~min}$ at room temperature. Labeling efficiency was evaluated by thin layer chromatography (TLC). The radiolabeled formulation was spotted on a TLC plate and run using saline as the mobile phase. The activity was measured using well-type gamma counter (Electronic Corporation of India, Mumbai). The percent radiolabeling efficiency was represented as percent ratio of bound activity to total activity. Stability of radiolabeled complex in mice plasma was determined by monitoring the radioactivity up to $24 \mathrm{~h}$ at ambient temperature.

Animal experimentations (biodistribution and efficacy study) were approved by Bhabha Atomic Research Centre Animal Ethics Committee, RMC, Parel, Mumbai, India. Study was carried out by protocol similar to that described by Peer and Margalit 2004 with slight modification (23). Briefly, female C57BL6 mice were randomly divided into three groups $(n=5)$. B16F10 murine lung carcinoma cells $\left(1 \times 10^{6}\right.$ cells in $100 \mu \mathrm{l}$ of PBS) were injected by subcutaneous route to the right armpit of mice, except one group (non-tumor-bearing). Tumors were allowed to develop up to the palpable size in two groups (tumor-bearing). The tumor-bearing groups were then injected with radiolabeled formulations (DL and FDL-a dose of $6 \mathrm{mg} / \mathrm{kg}$ body weight) through tail vein., where as non-tumor-bearing group received radiolabeled FDL formulation. After $24 \mathrm{~h}$, all animals were sacrificed by using over dose of thiopentone sodium anesthesia $(200 \mathrm{mg} / \mathrm{kg}$ of body weight by i. p. route). Necropsy was performed, and all vital organs along with injection site of solid tumors were collected. Radioactivity pertaining to each organ was measured by using gamma scintillation counter (Electronics Corporation of India, Mumbai, India). The percent uptake was calculated as ratio of radioactivity count of the organ to the total radioactivity administered.

\section{Efficacy Studies}

The study protocol was adopted from the report by Hwang and Peer $(23,24)$ with slight modification. Tumor was developed in C57BL6 mice by injecting B16F10 murine lung carcinoma cells $\left(1 \times 10^{6}\right.$ cells in $100 \mu$ of PBS $)$ subcutaneously to the right armpit of each animal. Mice were then separated into different groups; formulations (DL and FDL), DOX, 


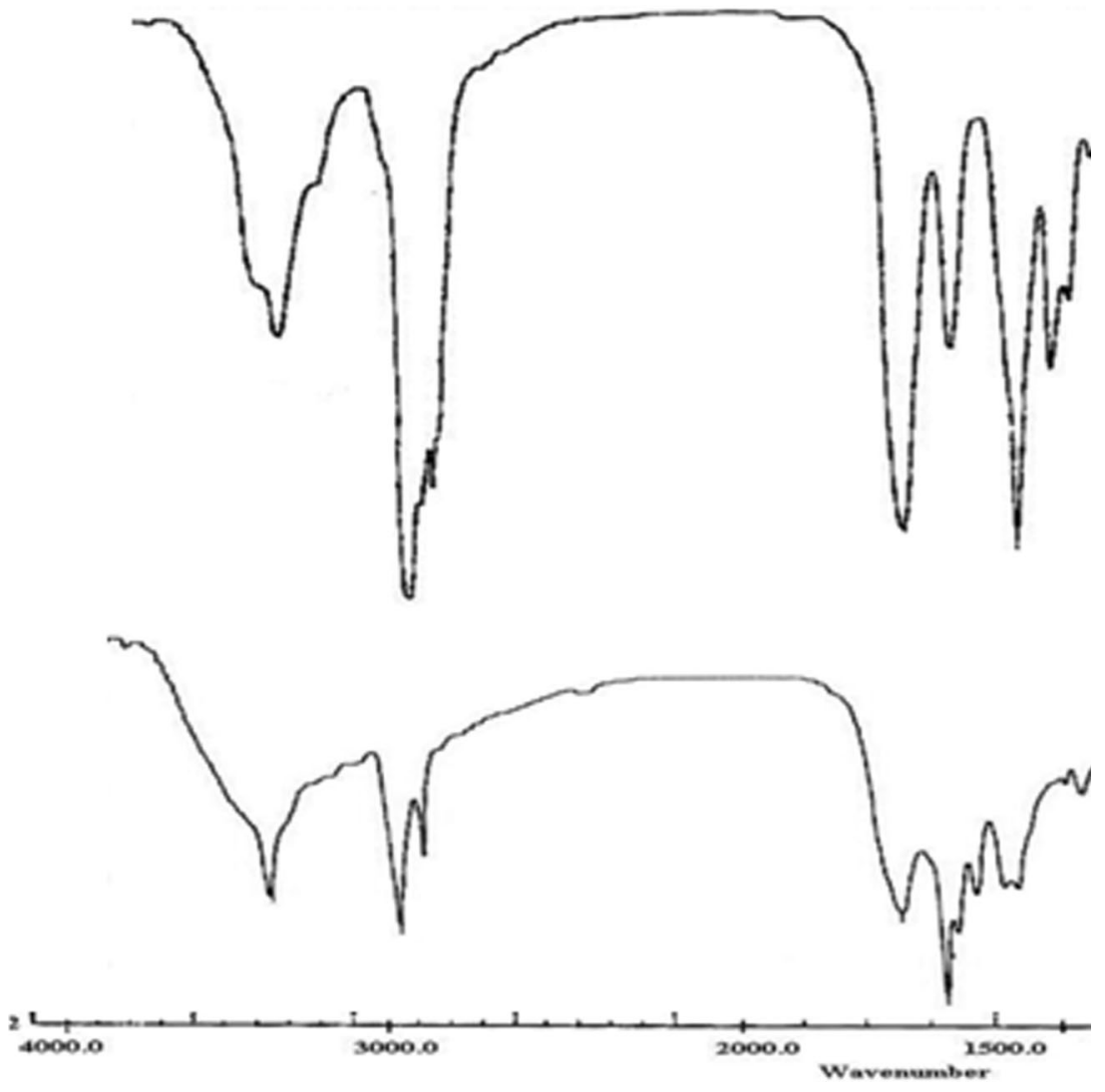

Fig. 1. FTIR spectra of $\mathrm{CP}$ and $\mathrm{CPF}$

control, and blank liposomes, and respective formulations were injected (dose $6 \mathrm{mg} / \mathrm{kg}$ ) through tail vein by i.v. route. Animals were observed and monitored for mortality and any abnormal behavior such as tremors, convulsions, salivation, and diarrhea until the completion of the study. Twelve days after dosing, mice were sacrificed. Tumors were separated and weighed. Tumor regression was calculated by the weight of the tumor, the higher the weight of the tumor, the lesser the regression. Efficacy of the delivery system was represented by regression in tumor weight and effect on $\mathrm{RBC}$ count.

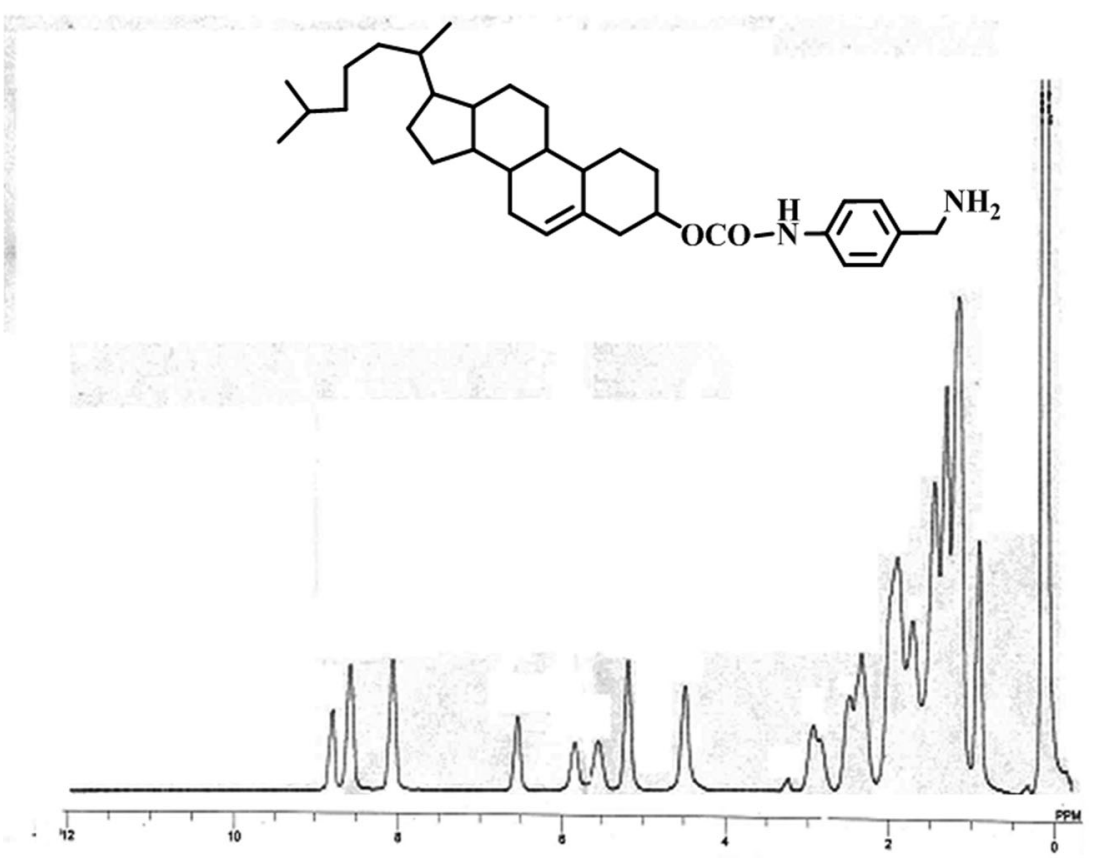

Fig. 2. NMR spectra of $\mathrm{CP}$ 


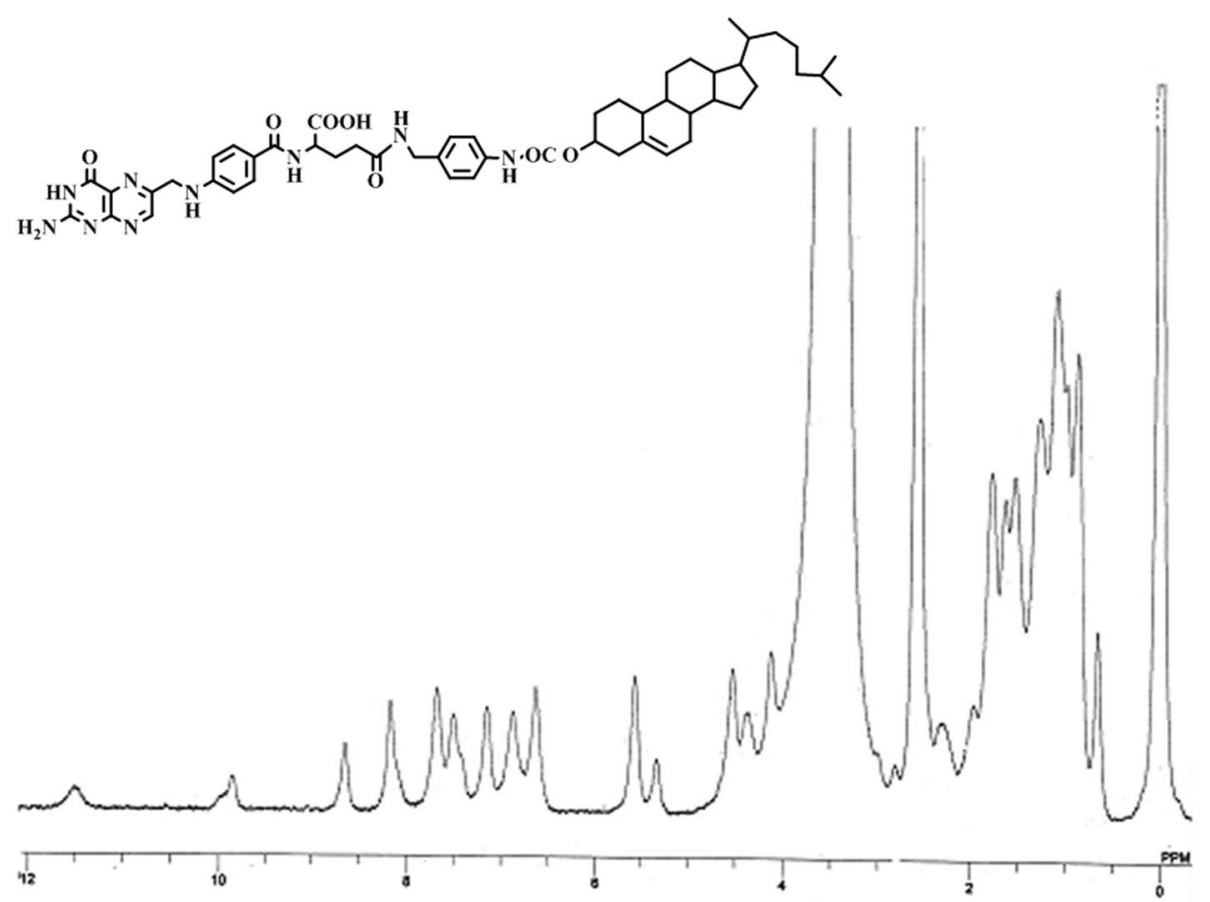

Fig. 3. NMR spectra of CPF

\section{Statistical Analysis of Data}

All data are reported as mean \pm standard deviation (SD), and differences between the groups were tested using Student's $t$ test at the level of significance of $p$ value $<0.05$.

\section{RESULTS}

\section{Synthesis and Characterization of Folic Acid-Conjugated Cholesterol}

The reaction was covalent conjugation of cholesterol chloroformate with p-aminobenzylamine (CP) followed by conjugation of CP complex with folic acid (CPF) $(17,18)$. FTIR was used to confirm the formation of the products. FTIR spectra of synthesized CP and CPF are depicted in Fig. 1a, b. In Fig. 1a, the peak at $3358 \mathrm{~cm}^{-1}$ corresponds to $\mathrm{NH}$ group, where as those at 1626 and $1518 \mathrm{~cm}^{-1}$ correspond to amide group, and peak at 1699 indicates urethane group. Figure $1 \mathrm{~b}$ depicts the FTIR spectrum of the CPF in which 1575 and $1535 \mathrm{~cm}^{-1}$ can be attributed to amide group, and $1626 \mathrm{~cm}^{-1}$ corresponds to secondary NH group. The structures

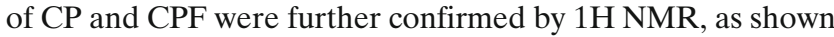

Table I. Chemical Composition of Uncoated Liposomes

\begin{tabular}{lcc}
\hline Composition & $\begin{array}{c}\text { Untagged liposomes } \\
\text { (DL) }(\mathrm{Mol} \%)\end{array}$ & $\begin{array}{c}\text { Folic acid tagged } \\
\text { liposomes } \\
\text { (FDL) (Mol\%) }\end{array}$ \\
\hline Phospholipon 90G & 52.3 & 52.3 \\
Phospholipon 90H & 34.8 & 34.8 \\
Cholesterol & 12.9 & 11.9 \\
CPF & - & 1.0 \\
\hline
\end{tabular}

in Figs. 2 and 3, respectively. The NMR spectra show characteristic signals which confirmed the formation of the compounds, viz CP and CPF.

\section{Preparation and Characterization of Delivery Systems for DOX}

The liposomal formulation of DOX was prepared by active loading using ammonium sulfate gradient method. FDL were prepared by insertion of folate-conjugated cholesterol (CPF) in the preparation of liposomes. The entrapment of DOX was $3028 \mu \mathrm{g} / 135 \mathrm{mg}$ of lipid. Table I reports the composition of liposomal formulations. The physicochemical properties of the liposomal formulations namely DOX content, size, and residual solvent levels are given in Table II. The residual levels of chloroform and methanol in the developed liposomal formulations were found to be very low, well below the ICH limits.

Table II. Physicochemical Characterization of FDL

Characteristic

Drug content ( $\mu \mathrm{g} / 135$-mg lipid)

Visual appearance and ease of redispersion

Particle size $(\mathrm{nm})$ before freeze drying

Particle size (nm) after freeze drying

Drug leakage (\%)

Organic solvent residue (ppm)
Folic acid tagged liposomes (FDL)

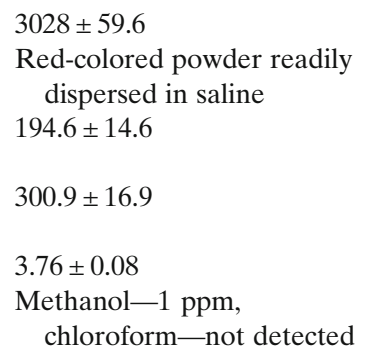

$3028 \pm 59.6$

Red-colored powder readily dispersed in saline $194.6 \pm 14.6$

$300.9 \pm 16.9$

$3.76 \pm 0.08$

Methanol-1 ppm, chloroform - not detected

All data is with $\pm \mathrm{SD} ; n=3$ 


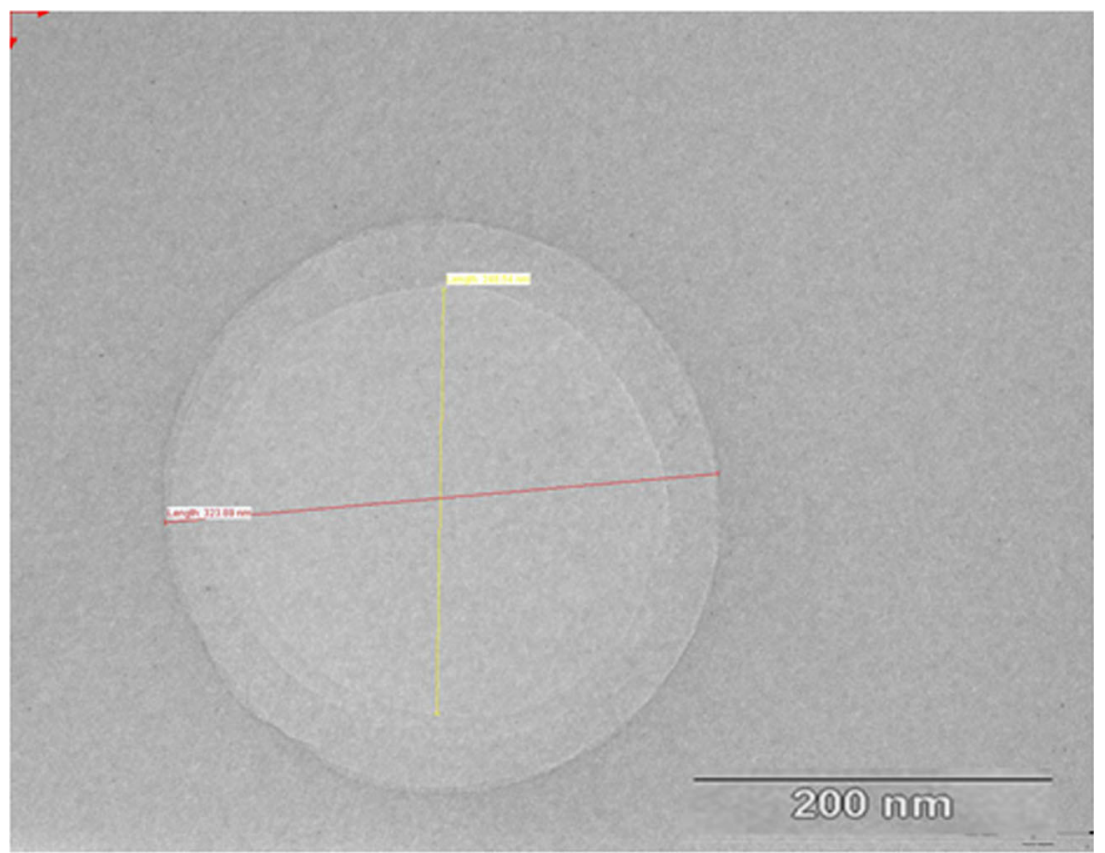

Fig. 4. Transmission electron microscopy image of FDL

TEM was used to image the DOX liposomes and to assess their size, shape and lamellarity. The DOX-loaded liposomes appear as bright spheres surrounded by dark thick layer showing large internal aqueous core surrounded by one or two lamellae (Fig. 4). Mean particle sizes obtained from TEM photomicrographs were in the range of $200-400 \mathrm{~nm}$, and size obtained by TEM was close to the size measured by photon correlation spectroscopy (Table II).
DSC scan of DOX (DSC thermogram A in Fig. 5) indicated the onset of endotherm at $216.61^{\circ} \mathrm{C}$ and peak at $234.17^{\circ} \mathrm{C}$. Blank liposomes (DSC thermogram D in Fig. 5) showed the endotherm peak at $94.36^{\circ} \mathrm{C}$, whereas in $\mathrm{DL}$, FDL (DSC thermograms $\mathrm{B}$ and $\mathrm{C}$, respectively in Fig. 5) showed the onset of endotherm at $206.09^{\circ} \mathrm{C}$ and attainment of peak at $210.85^{\circ} \mathrm{C}$. Thus, the DSC study of the developed liposomal formulations revealed the presence of the DOX in

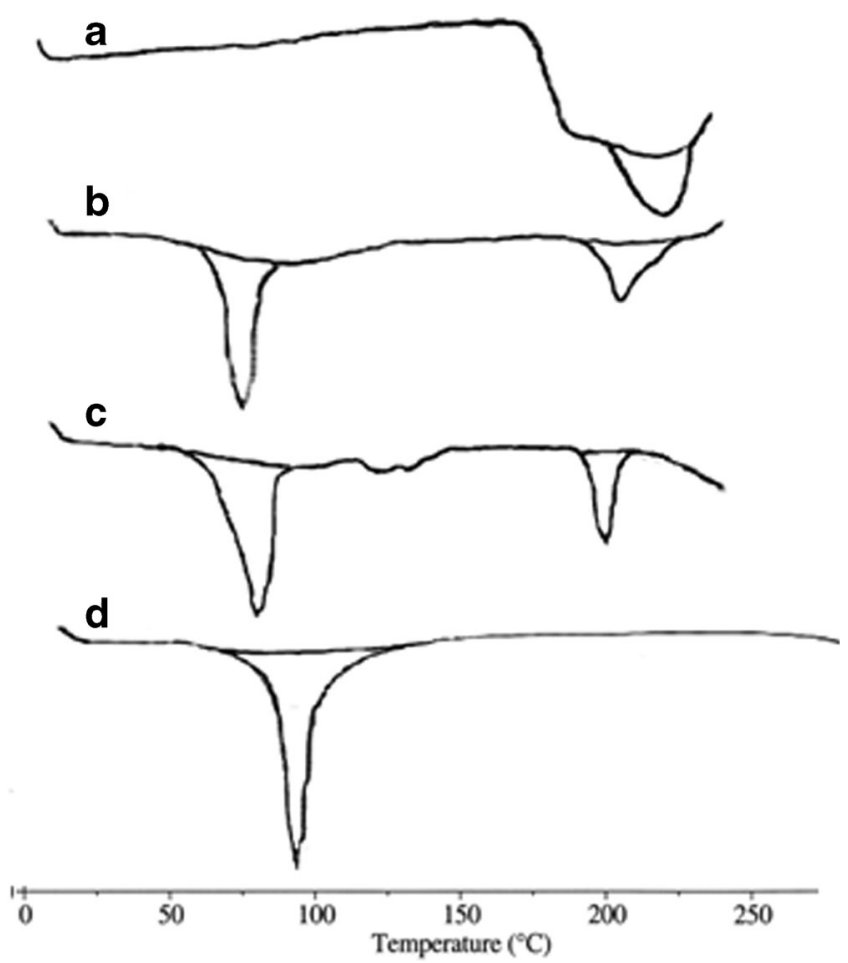

Fig. 5. DSC thermograms (a DOX, b DL, c FDL, and d blank liposomes) 
the liposomal system. In vitro DOX release from liposomes (Fig. 6) suggested that there is burst release of DOX (up to $28 \%$ ) for initial $10 \mathrm{~h}$ after which there is very small increase in release over the period of $48 \mathrm{~h}$ (up to $30 \%$ ).

\section{In Vitro Cell Line Evaluation}

\section{Receptor Expression}

Folic acid competition assay was carried out to establish the presence of folic acid receptor on the surface of B16F10 cell line. The uptake of DOX from folate-targeted delivery system was reduced from $25.42 \pm 0.89 \mu \mathrm{g}$ DOX/million cells to $19.19 \pm 1.07 \mu \mathrm{g}$ DOX/million cells in presence of $1 \mathrm{mM}$ folic acid (Fig. 7). The assay thus revealed the inhibition of uptake of the FDL system into B16F10 cells due to the presence of excess folic acid, indicating the presence of folic acid receptors on the surface of the B16F10 cells, which is responsible for the uptake.

\section{Cell Uptake Process}

Cellular uptake study indicated an increased uptake of FDL $(25.42 \pm 0.89 \mu \mathrm{g}$ DOX/million cells) as compared to that of DL $(17.99 \pm 1.30 \mu \mathrm{g}$ DOX/million cells $)$ and DOX $(10.58 \pm$ $1.21 \mu \mathrm{g} \mathrm{DOX} /$ million cells) (Fig. 8) due to presence of folate receptor on the cell surface, which promoted the uptake of FDL.

The results of fluorescence microscopy also suggested that there is an increase in accumulation of DOX inside the cells, in the case of FDL as compared to the conventional DL and DOX. The trend in accumulation of drug is as follows: FDL $>$ DL $>$ DOX.

\section{Optimization of Ligand Content in Delivery System}

Optimization of percent ligand content was carried out by measuring the uptake of the liposomal delivery system (FDL) with varying folate content in B16F10 cells. Results revealed increased uptake of DOX from $0.5 \mathrm{Mol} \%(21.89 \pm 2.32 \mu \mathrm{g})$ to $1.0 \mathrm{Mol} \%(25.42 \pm 1.98 \mu \mathrm{g})$ folate containing targeted delivery

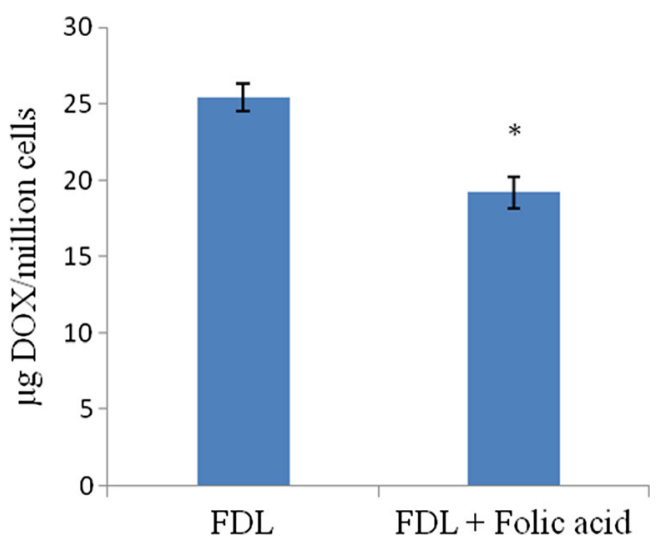

Fig. 7. Folic acid receptor expression assay in B16F10 cell. Uptake of folate-tagged DOX liposomes (equivalent to $50 \mu \mathrm{g} / \mathrm{ml}$ of DOX) was evaluated by fluorometry with or without presence of free folic acid (1 mM folic acid). Uptake of folate-tagged DOX liposome (FDL) was significantly reduced in presence of free folic acid. *Students $t$ test $p$ value $<0.05$

system due to presence of excess folate on the delivery system (Fig. 9). However, from 1.0 to $1.5 \mathrm{Mol} \%$ folate-targeted delivery system, there is not much increase in the folate uptake $(25.9 \pm 1.54 \mu \mathrm{g})$. This may be attributed to the saturation of the folate receptors.

\section{Cytotoxicity Assay}

MTT-based cytotoxicity assay was performed to compare the anticancer effect of the folate-targeted delivery systems against the A549 human lung cancer cells and B16F10 murine lung cancer cells. The $\mathrm{IC}_{50}$ values for $\mathrm{DOX}$, DL, and FDL were very close $1.36-2.10 \mu \mathrm{M}$ for A549 and $0.927-1.315 \mu \mathrm{M}$ for B16F10 cell line. This may be attributed to the fact that DOX is slowly released from the liposomal formulation. Also, the incubation time was $48 \mathrm{~h}$, which is considered to be small, and possibly, there is incomplete release of DOX from the delivery system. However, folate-conjugated delivery system had shown a marginally improved inhibitory potential as compared to untagged delivery system as shown in Table III.

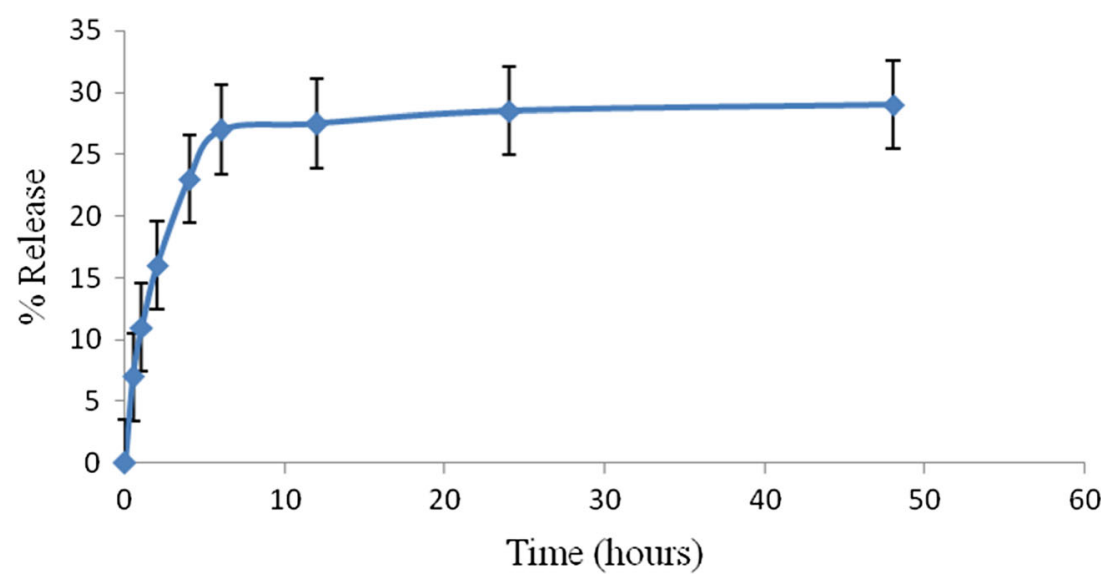

Fig. 6. In vitro drug release from FDL (reconstituted liposome filled in dialysis bag) in phosphate buffered saline $\mathrm{pH} 7.4$ medium using USP type I dissolution apparatus at $50 \mathrm{rpm}$ and $37 \pm 0.5^{\circ} \mathrm{C}$ 


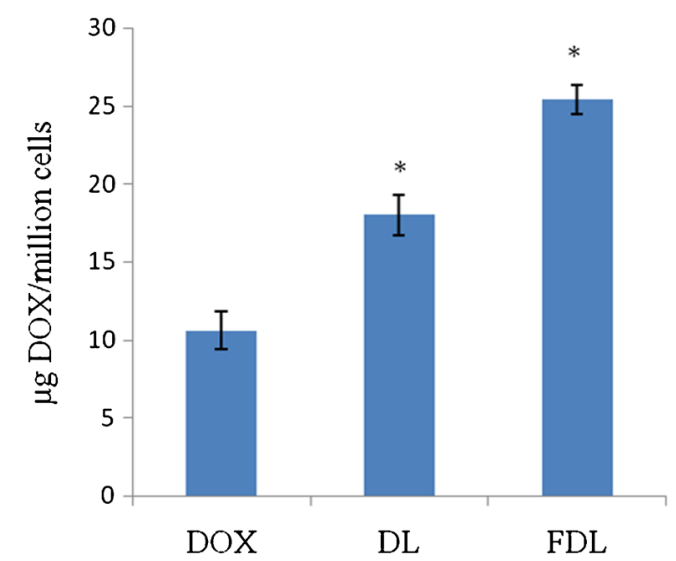

Fig. 8. Cell uptake study in B16F10 cell line. Uptake of folate-tagged DOX liposomes (equivalent to $100 \mu \mathrm{g} / \mathrm{ml}$ of DOX) was evaluated by fluorometry in folic acid-free media. Uptake of folate-tagged DOX liposome (FDL) was significantly higher as compared to untagged DOX liposome (DL) and free DOX. *Students $t$ test $p$ value $<0.05$

\section{In Vivo Studies}

\section{Acute Toxicity Studies}

Swiss Albino mice were administered with DOX and folate-tagged liposomes by IV route (dose, $6 \mathrm{mg} / \mathrm{kg}$ ) through tail vein. No changes in the skin, fur, eyes, and behavioral pattern were observed in any of the dosed animals. The animals of all the groups survived for the complete duration of the study. There was no significant difference in the increase in body weights and mean relative organ weights (Table IV) of the animals of the control group and the treated groups. However, histopathology studies of the heart revealed severe cardiotoxicity of animals treated with free DOX as compared to animals treated with FDL and the control group. Free DOX-treated group showed cytoplasmic vacuolation and loss of muscle striations with severe pathology, whereas FDL-treated group showed only mild pathological changes as compared to the control group.
Table III. MTT Assay of Delivery Systems

\begin{tabular}{lll}
\hline Delivery system & IC50 A549 $(\mu \mathrm{M})$ & IC50 B16F10 $(\mu \mathrm{M})$ \\
\hline Doxorubicin & 1.36 & 0.927 \\
DL & 2.23 & 1.404 \\
FDL & 2.10 & 1.315 \\
\hline
\end{tabular}

\section{Biodistribution Study}

Radiolabeling of the Liposomes. Freeze dried DL and FDL liposomes were reconstituted in saline and were radiolabeled with Technetium-99 $\mathrm{m}\left({ }^{99 \mathrm{~m}} \mathrm{Tc}\right)$, using stannous chloride as reducing agent, Radiolabeling conditions were optimized with respect to time of incubation and ratio of ${ }^{99 \mathrm{~m}} \mathrm{Tc}$ : liposomes. Radiolabeling efficiency of the liposomal system was found to be more than $98 \%$. The optimum ratio of ${ }^{99 \mathrm{~m}} \mathrm{Tc}$ : liposomes was found to be $3 \mathrm{mCi}: 25 \mathrm{mg}$, while optimum incubation time was found to be $10 \mathrm{~min}$. The developed radiolabeled complex was stable for $24 \mathrm{~h}$ in saline at $37 \pm$ $0.5^{\circ} \mathrm{C}$.

Biodistribution study was performed by injecting radiolabeled liposomal formulation through tail vein in tumor-bearing C57BL6 mice; gamma scintigraphic biodistribution profiles of DL and FDL are depicted in Fig. 10. FDL has shown different pattern of uptake compared to that of DL delivery system. FDL has shown reduced uptake of liposomes in the liver and spleen, and increased uptake to significant level in tumor ( $p$ value $<0.05$ ).

\section{In Vivo Efficacy Study in Solid Tumor Model}

Tumor-bearing C57BL6 mice were sacrificed 12 days after a single dose of either DOX or formulations, and tumor weight was taken as measure of regression in tumor growth. The tumor volume was reduced in the treatment group as compared to the control untreated group (Figs. 11 and 12). The growth of tumor in mice treated with FDL was

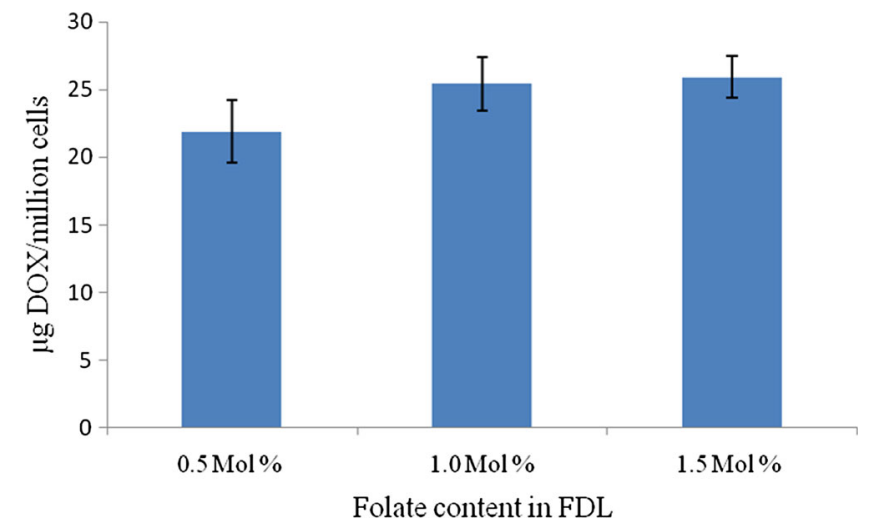

Fig. 9. Optimization of folate content by (liposomes prepared with varying content of folic acid $0.5,1.0$, and $1.5 \mathrm{Mol} \%$ containing equivalent to $100 \mu \mathrm{g} / \mathrm{ml}$ of DOX) in delivery system by cell uptake study in B16F10 cell line 
Table IV. In Vivo Acute Toxicity Results in Swiss Albino Mice

\begin{tabular}{|c|c|c|c|c|c|c|}
\hline \multirow[t]{2}{*}{ Group } & \multirow[t]{2}{*}{$\%$ gain in body weight } & \multicolumn{5}{|c|}{$\%$ mean relative organ weight } \\
\hline & & Lung & Heart & Kidney & Spleen & Liver \\
\hline Control & $9.0 \pm 0.15$ & $0.95 \pm 0.05$ & $0.42 \pm 0.05$ & $1.03 \pm 0.07$ & $0.49 \pm 0.06$ & $5.21 \pm 0.06$ \\
\hline Blank & $10.1 \pm 0.19$ & $1.02 \pm 0.06$ & $0.43 \pm 0.04$ & $1.10 \pm 0.06$ & $0.44 \pm 0.02$ & $5.90 \pm 0.08$ \\
\hline DOX & $7.8 \pm 0.22$ & $0.91 \pm 0.07$ & $0.42 \pm 0.08$ & $1.08 \pm 0.09$ & $0.45 \pm 0.06$ & $5.32 \pm 0.09$ \\
\hline FDL & $10.1 \pm 0.21$ & $0.92 \pm 0.06$ & $0.43 \pm 0.04$ & $1.05 \pm 0.08$ & $0.55 \pm 0.05$ & $5.45 \pm 0.06$ \\
\hline
\end{tabular}

All data is with $\pm \mathrm{SD} ; n=3$

significantly inhibited when compared to those treated with DL and free DOX ( $p$ value $<0.5)$. The effect of developed FDL systems on RBC count was studied, and results revealed (Fig. 13) less reduction of RBC count in FDL-treated mice as compared to the DL-treated and DOX-treated group.

\section{DISCUSSION}

Liposomal systems are increasingly being used for delivery of anticancer agents because of their ability to accumulate in the tumor cells due to the enhanced permeation and retention (EPR) effect of cancer cells. In addition, the surface of liposomes can be modified with ligands for receptors over expressed on cancer cells; hence, active targeting is also possible. Previous studies demonstrated that the folate receptor is highly expressed in cancer cells (5-10). Therefore, this membrane receptor appears as an attractive target to develop appropriate folate-based drug delivery systems for anticancer therapy. Several attempts in the past have been tried for active targeting using folic acid as targeting ligand by conjugation of folic acid to lipid or polymer using PEG as linker (13-15). The present study aimed to explore the use of p-aminobenzylamine (PABA) as a linker which provides versatility of anchoring targeting ligands to delivery system. Conjugation of folic acid with cholesterol was carried out using PABA and then subsequent incorporation of folate- tagged cholesterol in the liposomes. Cholesterol chloroformate was linked to p-aminobenzylamine, and this complex was then further reacted with folic acid by amidation reaction to give cholesterol-linked folic acid-targeted conjugate (Fig. 14). These synthesized compounds were then incorporated into liposomal system to evaluate the targeting potential of folic acid tagged systems.

In the present work, DOX was used as a model drug for the evaluation of folate-based bioconjugated liposomal delivery system against solid tumors. DOX is a widely used anticancer agent and is active against various types of cancers. DOX is reported with severe toxicity like cardiomyopathy, secondary malignancies, extravasation and tissue necrosis, and severe myelosuppression (25). There are two liposomal formulations of DOX, which are approved for clinical use; these are Myocet ${ }^{\circledR}$ and Doxil®. DOX loading in liposomes is generally carried out by remote loading method, which is based on the concentration gradient.

In the present investigation, ammonium sulfate gradient method was used for DOX loading. The formulation and process of preparation of liposomes were optimized with respect to composition of phospholipids and cholesterol, sonication time, incubation time, and cryoprotectant ratio so as to achieve maximum DOX entrapment and optimum particle size.

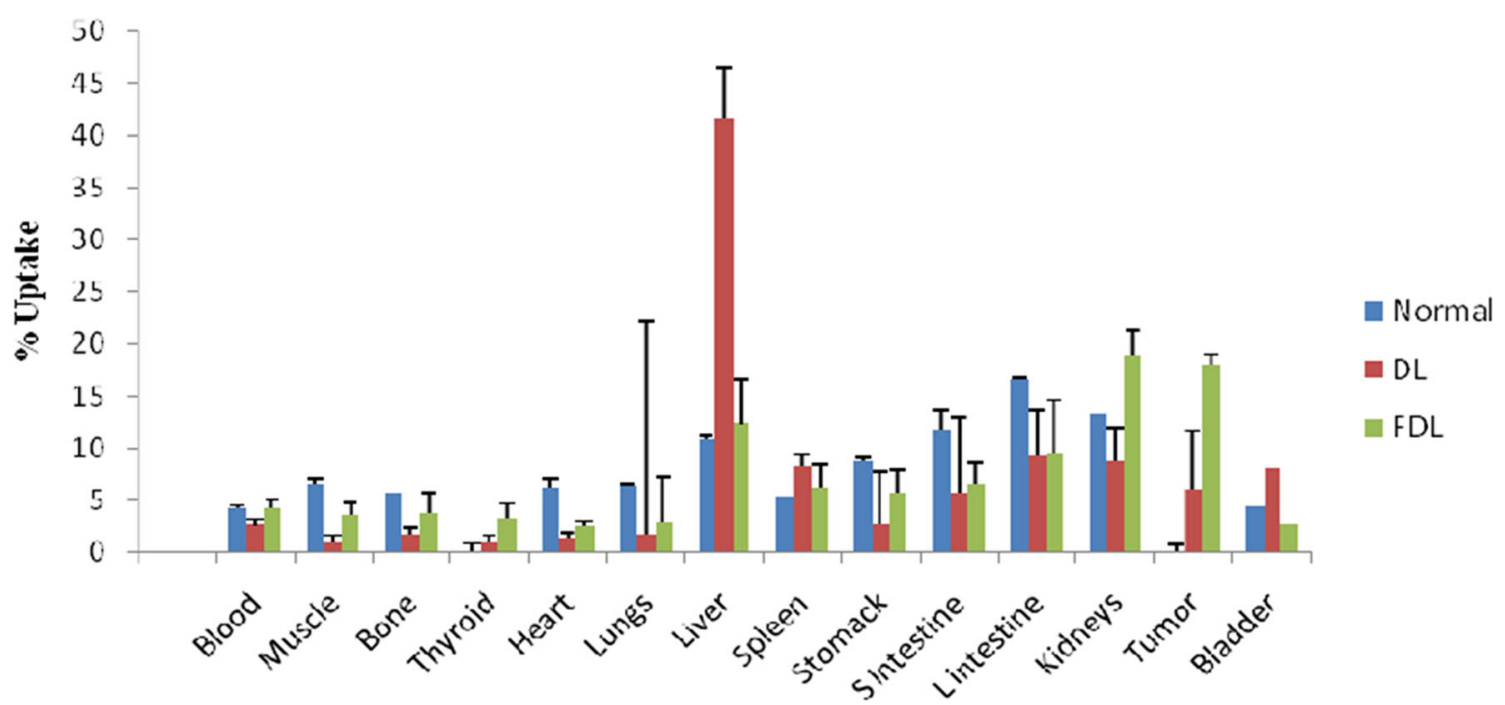

Fig. 10. In vivo biodistribution study. Percent radioactivity in various organs of solid tumor-bearing C57BL6 mice 24 h after IV administration of ${ }^{99 \mathrm{~m}}$ Tc-tagged folate-conjugated liposome (FDL) and untagged (DL) delivery system (dose, equivalent to $6 \mathrm{mg} / \mathrm{kg}$ of DOX) and percent radioactivity in various organs of non-tumor-bearing C57BL6 mice (normal) $24 \mathrm{~h}$ after IV administration of ${ }^{99 \mathrm{~m}}$ Tc-tagged DOX (dose, $6 \mathrm{mg} / \mathrm{kg}$ ) 


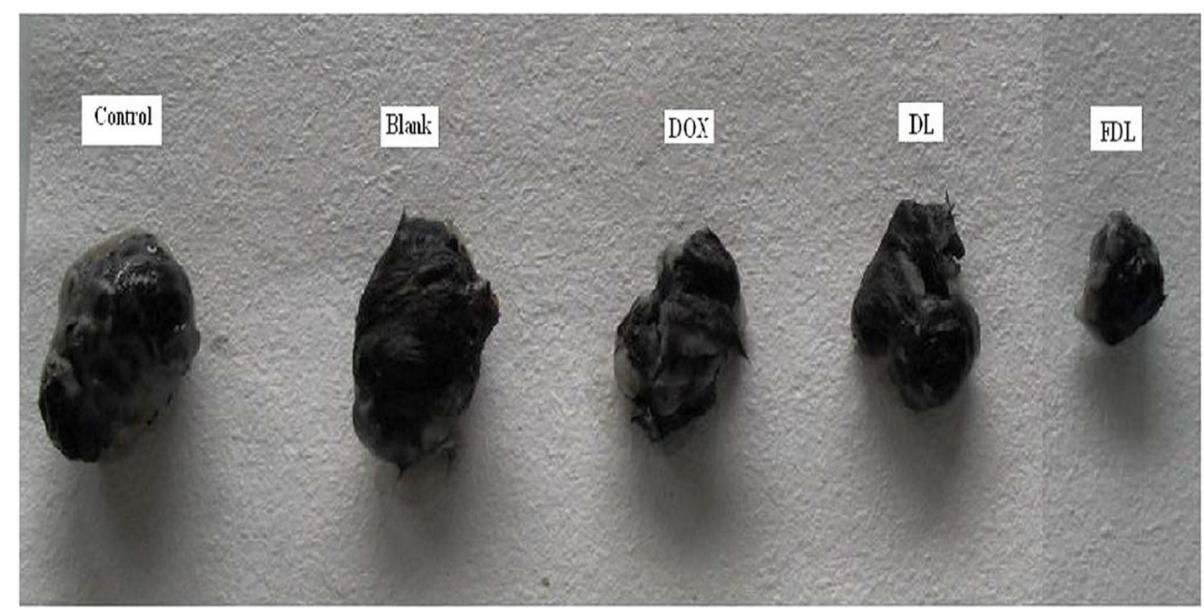

Fig. 11. Pictographical representation of tumor efficacy study carried out in solid tumor-bearing C57BL6 mice. Representative tumors 12 days after a single dose of blank liposome, FDL, DL, and DOX $(6 \mathrm{mg} / \mathrm{kg})$

It is well known that covering colloidal particles with hydrophilic, nonionic polymers such as polyethylene glycol (PEG) or poloxamer greatly increase their circulation time-by steric stabilization of the colloidal delivery system - and avoid the reticuloendothelial system (RES) uptake. Surface stabilization of liposomes can be achieved by adsorption of coating polymer on the surface of the colloidal delivery system or by the covalent-linked polymer incorporated into the delivery system $(13,26-28)$. In the present study, liposomes were coated with $1 \%$ poloxamer F127 by physical adsorption method prior to freeze drying. The particle size of DL liposomes was increased from 194 to $300 \mathrm{~nm}$, indicating the coating of liposomes.

To improve the stability of liposomes, they were freeze dried. However, freeze drying process can lead to destruction of membrane function of the liposomes, substantial leakage of the entrapped compound, which can be controlled and reduced by using appropriate cryoprotectant while freeze drying. Trehalose was used as cryoprotectant as it had shown less DOX leakage (less than $4 \%$ ), and vesicle size was also not affected to a great extent. Different ratios of trehalose:lipid were tried, and 4:1 was found to be most effective in terms of maintaining particle size as well as avoiding DOX leakage.

The freeze dried formulation appeared as red-colored fluffy powder, which was easily redispersed upon reconstitution in sterile saline. In vitro release study of the liposomes was carried out to understand percent DOX leakage from the delivery system in PBS $\mathrm{pH} 7.4$; results suggested that there is a burst release of DOX (up to $28 \%$ ) for initial $10 \mathrm{~h}$ after which there is very small increase in release over the period of $48 \mathrm{~h}$ (up to $30 \%$ ). The developed delivery system is required to release DOX after reaching target site, i.e., tumor. From in vitro release pattern, it can be inferred that only $30 \%$ of DOX is released in plasma and around $70 \%$ of DOX reaches the target tumor cells.

In vitro cell line studies were carried out in A549 human lung cancer cell lines and B16F10 murine lung carcinoma cell lines. The receptor expression assay carried out in B16F10 cell line confirmed the presence of folic acid on cell surface, as the uptake of folate-conjugated liposomes was reduced. This

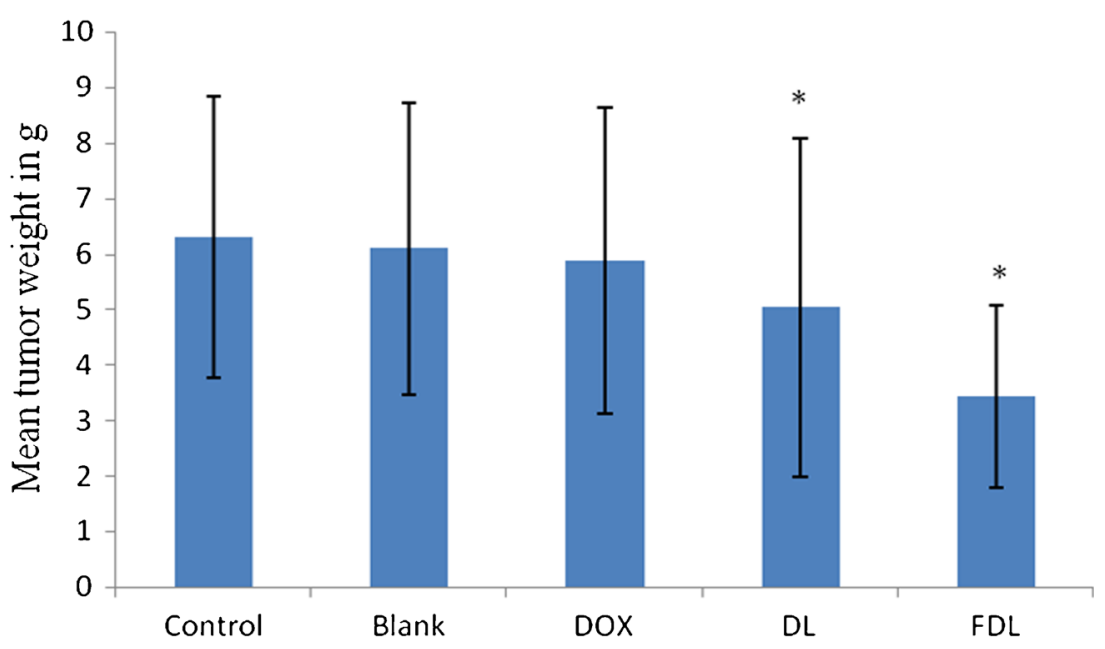

Fig. 12. Mean tumor weight analysis $(n=5)$ in solid tumor-bearing C57BL6 mice. Tumor weights 12 days after a single dose of blank liposome, FDL, DL, and DOX $(6 \mathrm{mg} / \mathrm{kg}) . * p$ value $<0.05$ ( $t$ test) 


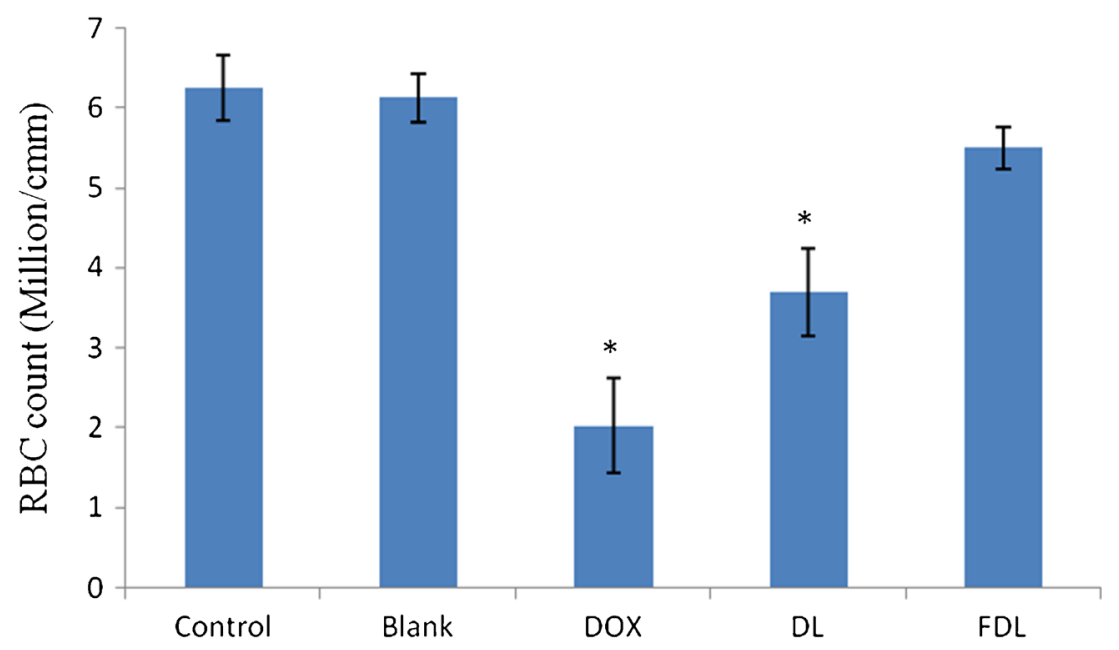

Fig. 13. Effect on RBC in solid tumor-bearing C57BL6 mice. RBC count 12 days after a single dose of blank liposome, FDL, DL, and DOX $(6 \mathrm{mg} / \mathrm{kg})$. * $p$ value $<0.05$ ( $t$ test)<smiles>CC(=O)OC1CCC2C(=CCC3C2CCC2C(C(C)CCCC(C)[In])CCC23)C1</smiles>

Cholesterol chlorof ormate

Para amino4-(aminomethyl)aniline<smiles>CC(C)CCCC(C)C1CCC2C1CCC1C3CCC(OC(=O)Nc4ccc(CN)cc4)CC3=CCC12</smiles>

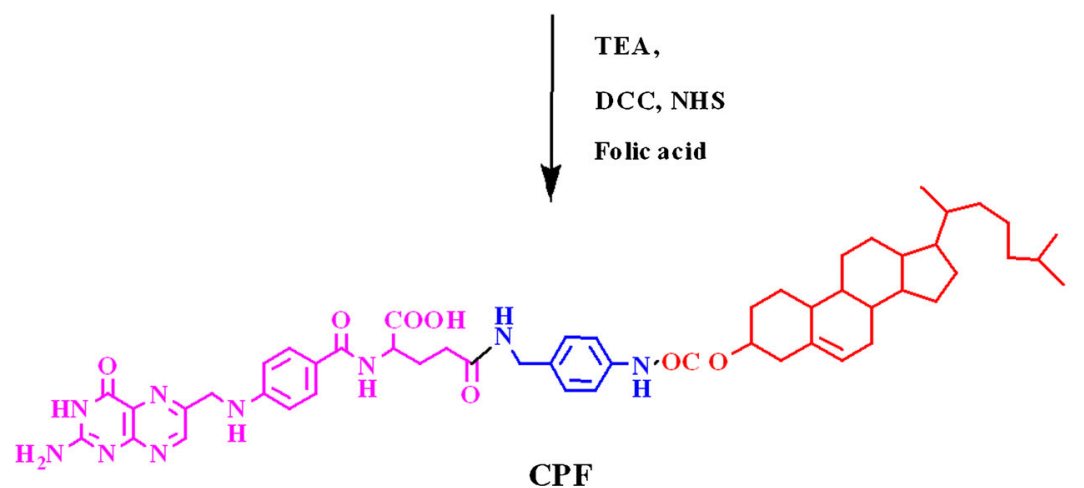

Fig. 14. Schematic representation of preparation of cholesterol-conjugated folic acid. Conjugation of cholesterol chloroformate to p-aminobenzylamine and then further reaction with folic acid 
indicates the competitive inhibition of receptor-binding site on the surface by folic acid and resulting in reduced uptake of folate-conjugated delivery system in the cell. Similarly, in cell uptake studies, the uptake of FDL was increased as compared to conventional DL and free DOX (20).

In vitro cytotoxicity studies carried out in A549 human lung cancer cell lines and B16F10 murine lung carcinoma cell lines revealed enhanced uptake of FDL as compared to DL. Acute toxicity study in healthy mice did not show any signs of toxicity after administration of single dose of formulation as compared to DOX which is reported to be highly cardiotoxic. Thus, as reported previously, (29) our studies have also shown that the liposomal formulation is able to reduce toxicity. Biodistribution study in solid tumor-bearing C57BL6 mice showed that FDL is taken up to a greater extent in tumor as compared to DL. Also, FDL showed reduced uptake in the liver and spleen, and uptake increased to a significant level in tumor. Similar observations were recorded by Low et.al, in an uptake study of PEG-folate-tagged liposomal system, wherein uptake in tumor was increased due to folate tagging to the liposomal delivery system (30). The tumor growth in subcutaneously administered B16F10 melanoma-bearing mice treated with FDL was inhibited to a greater extent, when compared with those treated with conventional DL liposomes and free DOX. Therefore, these results indicate that FDL exhibits inhibition of tumor growth more efficiently than conventional DL liposomes. Myelosupression is one of the major side effects of DOX (31), which is reduced markedly in the FDL treated groups, evidenced by the RBC counts. The results showed that the targeted FDL liposomes showed significantly better protection with less toxicity as compared to conventional DL liposome and free DOX.

Through these experiments, it is demonstrated that FDL is selectively internalized into FR-expressing tumor cells including B16F10 and A549 cells as well as B16F10 melanomabearing mice. Moreover, we have highlighted that FDL will lead to a reduction in toxicity of DOX. Although, we have shown the importance of the folate targeting, further experiments with more cell lines and chronic toxicity and efficacy studies in higher animals should be conducted to fully realize the potential of these systems.

\section{CONCLUSION}

The present investigation had suggested that application of the p-aminobenzylamine as linker for conjugation of ligands like folic acid on cholesterol. Such conjugation provides versatility and enables the researchers to anchor different targeting ligands with simple reaction procedures. Further, such conjugated lipid can be easily incorporated in the liposomal drug delivery systems. The study has conjugated folic acid as a ligand, and liposomal systems prepared using it has shown good targeting potential to cancer cells. Further investigations in various types of tumors-expressing folic acid will ensure the merit of the developed folate-targeted liposomal system.

\section{ACKNOWLEDGMENTS}

The authors are thankful to BRNS-DAE for providing financial assistance for the present investigation (Sanction no. 2007/17/BRNS).

\section{COMPLIANCE WITH ETHICAL STANDARDS}

All the animal studies were approved by independent ethics committee of Bhabha Atomic Research Centre, Mumbai, India. All the procedures involved in the animal studies were performed in accordance with the recommendations of $\mathrm{NIH}$ guidelines for the proper use and care of laboratory animals. In addition, the study was approved by independent Animal Ethics Committee of Bombay College of Pharmacy, and experiment was performed as per the OECD guidelines.

Conflict of Interest The authors declare that they have no competing interests.

\section{REFERENCES}

1. Abraham SA, Waterhouse DN, Mayer LD, Cullis PR, Madden TD, Bally MB. The liposomal formulation of doxorubicin. Methods Enzymol. 2005;391:71-97.

2. Chabner BA. General principles of cancer chemotherapy. Goodman and Gilman's the pharmacological basis of therapeutics. New York: McGraw-Hill; 2011. p. 1667-76.

3. Shrivastava AR SH, Roy SK, Galdhar CN, Shirole R, Gaikwad RV, Rajan MR, et al. Nanoparticle based DPI formulation for active targeting of etoposide in lung cancer. Respir Drug Deliv. 2012;2:427-32.

4. Maeda H, Bharate GY, Daruwalla J. Polymeric drugs for efficient tumor-targeted drug delivery based on EPR-effect. Eur J Pharm Biopharm. 2009;71(3):409-19.

5. Campbell IG, Jones TA, Foulkes WD, Trowsdale J. Folatebinding protein is a marker for ovarian cancer. Cancer Res. 1991;51(19):5329-38.

6. Walters CL, Arend RC, Armstrong DK, Naumann RW, Alvarez RD. Folate and folate receptor alpha antagonists mechanism of action in ovarian cancer. Gynecol Oncol. 2013;131(2):493-8.

7. Parker N, Turk MJ, Westrick E, Lewis JD, Low PS, Leamon CP. Folate receptor expression in carcinomas and normal tissues determined by a quantitative radioligand binding assay. Anal Biochem. 2005;338(2):284-93.

8. Dainty LA, Risinger JI, Morrison C, Chandramouli GVR, Bidus MA, Zahn C, et al. Overexpression of folate binding protein and mesothelin are associated with uterine serous carcinoma. Gynecol Oncol. 2007;105(3):563-70.

9. Clarhaut J, Fraineau S, Guilhot J, Peraudeau E, TranoyOpalinski I, Thomas M, et al. A galactosidase-responsive doxorubicin-folate conjugate for selective targeting of acute myelogenous leukemia blasts. Leuk Res. 2013;37(8):948-55.

10. Lu Y, Low PS. Folate-mediated delivery of macromolecular anticancer therapeutic agents. Adv Drug Deliv Rev. 2012;64:342-52.

11. Mastrobattista E, Koning GA, Storm G. Immunoliposomes for the targeted delivery of antitumor drugs. Adv Drug Deliv Rev. 1999;40(1):103-27.

12. Vonarbourg A, Passirani C, Saulnier P, Benoit J-P. Parameters influencing the stealthiness of colloidal drug delivery systems. Biomaterials. 2006;27(24):4356-73.

13. Gao W, Xiang B, Meng T-T, Liu F, Qi X-R. Chemotherapeutic drug delivery to cancer cells using a combination of folate targeting and tumor microenvironment-sensitive polypeptides. Biomaterials. 2013;34(16):4137-49.

14. Xiang G, Wu J, Lu Y, Liu Z, Lee RJ. Synthesis and evaluation of a novel ligand for folate-mediated targeting liposomes. Int J Pharm. 2008;356(1):29-36.

15. Yang C, Chen H, Zhao J, Pang X, Xi Y, Zhai G. Development of a folate-modified curcumin loaded micelle delivery system for cancer targeting. Colloids Surf B: Biointerfaces. 2014;121:206-13.

16. Guo W, Lee T, Sudimack J, Lee RJ. Receptor-specific delivery of liposomes via folate-PEG-chol. J Liposome Res. 2000;10:179-95. 
17. Letsinger RL, Zhang GR, Sun DK, Ikeuchi T, Sarin PS. Cholesteryl-conjugated oligonucleotides: synthesis, properties, and activity as inhibitors of replication of human immunodeficiency virus in cell culture. Proc Natl Acad Sci. 1989;86(17):65536.

18. Yoo HS, Park TG. Folate-receptor-targeted delivery of doxorubicin nano-aggregates stabilized by doxorubicin-PEG-folate conjugate. J Control Release. 2004;100(2):247-56.

19. Haran G, Cohen R, Bar LK, Barenholz Y. Transmembrane ammonium sulfate gradients in liposomes produce efficient and stable entrapment of amphipathic weak bases. Biochim Biophys Acta (BBA) Biomembr. 1993;1151(2):201-15.

20. Lu Y, Wu J, Wu J, Gonit M, Yang X, Lee A, et al. Role of formulation composition in folate receptor-targeted liposomal doxorubicin delivery to acute myelogenous leukemia cells. Mol Pharm. 2007;4(5):707-12.

21. Yoshida T, Oide N, Sakamoto T, Yotsumoto S, Negishi Y, Tsuchiya S, et al. Induction of cancer cell-specific apoptosis by folate-labeled cationic liposomes. J Control Release. 2006;111(3):325-32.

22. Singh DJ, Lohade AA, Parmar JJ, Hegde DD, Soni P, Samad A, et al. Development of chitosan-based dry powder inhalation system of cisplatin for lung cancer. Indian J Pharm Sci. 2012;74(6):521.

23. Peer D, Margalit R. Tumor-targeted hyaluronan nanoliposomes increase the antitumor activity of liposomal doxorubicin in syngeneic and human xenograft mouse tumor models. Neoplasia (NY). 2004;6(4):343.
24. Hwang T, Han HD, Song CK, Seong H, Kim JH, Chen X, et al, editors. Anticancer Drug-phospholipid conjugate for enhancement of intracellular drug delivery. Macromolecular symposia; Wiley Online Library; 2007.

25. Rahman A, More N, Schein PS. Doxorubicin-induced chronic cardiotoxicity and its protection by liposomal administration. Cancer Res. 1982;42(5):1817-25.

26. Chien YW, Cabana BE, Mares SE. Novel drug delivery systems: fundamentals, developmental concepts, biomedical assessments. M. Dekker; 1982.

27. Guo J-x, Q-n P, Jiang G, Huang L, Tong Y. Chitosan-coated liposomes: characterization and interaction with leuprolide. Int $\mathrm{J}$ Pharm. 2003;260(2):167-73.

28. Hong R-L, Huang C-J, Tseng Y-L, Pang VF, Chen S-T, Liu J-J, et al. Direct comparison of liposomal doxorubicin with or without polyethylene glycol coating in C-26 tumor-bearing mice is surface coating with polyethylene glycol beneficial? Clin Cancer Res. 1999;5(11):3645-52.

29. Gabizon A, Catane R, Uziely B, Kaufman B, Safra T, Cohen R, et al. Prolonged circulation time and enhanced accumulation in malignant exudates of doxorubicin encapsulated in polyethyleneglycol coated liposomes. Cancer Res. 1994;54(4):987-92.

30. Lee RJ, Low PS. Delivery of liposomes into cultured KB cells via folate receptor-mediated endocytosis. J Biol Chem. 1994;269(5):3198-204.

31. Bally MB, Nayar R, Masin D, Cullis PR, Mayer LD. Studies on the myelosuppressive activity of doxorubicin entrapped in liposomes. Cancer Chemother Pharmacol. 1990;27(1):13-9. 